\title{
Posterior corneal curvature changes following Refractive Small Incision Lenticule Extraction
}

\author{
This article was published in the following Dove Press journal: \\ Clinical Ophthalmology \\ 21 July 2015 \\ Number of times this article has been viewed
}

\author{
Sri Ganesh \\ Utsav Patel \\ Sheetal Brar \\ Phaco and Refractive Surgery \\ Department, Nethradhama \\ Superspeciality Eye Hospital, \\ Bengaluru, Karnataka, India
}

Correspondence: Utsav Patel Phaco and Refractive Surgery Department, Nethradhama Superspeciality Eye Hospital, \# 256/I4, Kanakapura Main Road, 7th Block, Jayanagar, Bengaluru 560 070, Karnataka, India

Tel +9l 8026088000

Fax +91 8026633770

Email utsav5093@gmail.com
Purpose: To compare the posterior corneal curvature changes, in terms of corneal power and asphercity, following Refractive Small Incision Lenticule Extraction (ReLEx SMILE) procedure for low, moderate, and high myopia.

Methods: This retrospective, non randomized, comparative, interventional trial; included 52 eyes of 26 patients, divided in three groups: low myopia (myopia $\leq 3 \mathrm{D}$ [diopters] spherical equivalent [SE]), moderate myopia (myopia $>3 \mathrm{D}$ and $<6 \mathrm{D} \mathrm{SE}$ ), and high myopia (myopia $\geq 6$ D SE). All patients were treated for myopia and myopic astigmatism using ReLEx SMILE. The eyes were examined pre-operatively and 3 months post-operatively using SCHWIND SIRIUS, a three-dimensional rotating Scheimpflug camera with a Placido disc topographer to assess corneal changes with regard to keratometric power and asphericity of the cornea.

Results: A statistically significant increase in mean keratometric power in the 3, 5, and $7 \mathrm{~mm}$ zones of the posterior corneal surface compared with its pre-ReLEx SMILE value was detected after 3 months in the moderate myopia group (pre-operative [pre-op] $-6.14 \pm 0.23$, post-operative [post-op] $-6.29 \pm 0.22, P<0.001$ ) and high myopia group (pre-op $-6.19 \pm 0.16$, post-op $-6.4 \pm 0.18, P<0.001$ ), but there was no significant change in keratometric power of the posterior surface in the low myopia group (pre-op $-5.87 \pm 0.17$, post-op $-6.06 \pm 0.29, P=0.143$ ). Asphericity ( $Q$-value) of the posterior surface changed significantly $(P<0.001)$ after ReLEx SMILE in the moderate myopia group in the 3,5 , and $7 \mathrm{~mm}$ zones, and in the high myopia group in the 3 and $7 \mathrm{~mm}$ zones; but there was no significant change in the $Q$-value in the low myopia group in all three zones (pre-op $0.23 \pm 0.43$, post-op $-0.40 \pm 0.71, P=0.170)$, and in the high myopia group in the $5 \mathrm{~mm}$ zone $(P=0.228)$.

Conclusion: ReLEx SMILE causes significant changes in posterior corneal keratometric power and asphericity in moderate and high myopia, but the effect is subtle and insignificant in low myopia.

Keywords: ReLEx SMILE, Refractive Small Incision Lenticule Extraction, posterior curvature, corneal keratometric power, corneal asphericity

\section{Introduction}

The aim of refractive surgery is to create emmetropia by altering the shape of the cornea. Most corneal surface changes take place within the anterior corneal surface, which accounts for $+48-+50$ diopters (D) of refractive power because of the large difference indices of refraction between air and the cornea; the posterior corneal surface provides approximately $-6 \mathrm{D}$ of refractive power. The anterior corneal surface is reshaped directly during refractive surgery and has been studied largely by corneal topography. ${ }^{1-4}$ The posterior corneal surface may also change, not from direct application of refractive techniques but from intraocular pressure (IOP) changes and post-operative corneal thinning, as in radial keratotomy. 5,6

Since it is believed that the first sign of kerectasia appears on the posterior corneal surface $^{7-10}$ and not on the anterior, the importance of recognizing a change in the posterior corneal surface after refractive surgery deserves attention. 
Refractive Small Incision Lenticule Extraction (ReLEx SMILE) has recently evolved as an all-femtosecond, minimally invasive technique which involves creation of a refractive lenticule followed by its extraction through a $2 \mathrm{~mm}$ incision. ${ }^{11,12}$ It offers significant advantages over laserassisted in situ keratomileusis (LASIK), in terms of being flapless, better biomechanical stability, ${ }^{13}$ less post-operative dry eyes, ${ }^{14}$ and induced aberrations. ${ }^{15}$ It has been proposed that this technique may be better and more stable for treating higher powers compared to LASIK, as the biomechanical strength after ReLEx SMILE is not compromised much due to intact Bowman's membrane and conservation of strong anterior corneal lamellae. Also, the residual stromal bed thickness is stated to be more compared to LASIK, as the cap also contributes to the residual bed thickness.

It has been observed that mild "keratectasia" of the cornea may be common early after LASIK as suggested by increased negative keratometric diopters and oblate asphericity of the posterior corneal curvature. ${ }^{716}$ However, not much is known about changes in the posterior corneal curvature following ReLEx SMILE.

Hence, this study has been undertaken with the aim of comparing the posterior corneal curvature changes in terms of keratometric power and asphericity, following ReLEx SMILE for low, moderate, and high myopia.

\section{Methods}

This retrospective study included eligible patients of both sexes, who underwent ReLEx SMILE for correction of myopia and myopic astigmatism between February 2014 and June 2014 at our center and included patients between 21 and 40 years of age, stable corneal conditions within the last 12 months, stable refraction since past 12 months $(<0.5 \mathrm{D}$ change within past 12 months), healthy ocular surface with stable tear film, and discontinuation of soft contact lenses 1 week and rigid contact lenses 3 weeks prior to surgery.

Patients who had thin corneas (corneal pachymetry $<480 \mu$ ), any ectatic condition of the cornea including keratoconus, Pellucid marginal degeneration, corneal scars, severe dry eye, and patients with any other ocular morbidity leading to loss of vision, were excluded from the study.

All patients underwent a thorough pre-operative evaluation including uncorrected distance visual acuity and corrected distance visual acuity, manifest and cycloplegic refraction, IOP measurement, slit lamp biomicroscopy examination, dilated fundus examination, dry eye assessment, topography
(Orbscan IIz [Bausch \& Lomb, Bridgewater, NJ, USA] and SIRIUS [SCHWIND eye-tech-solutions GmbH \& Co. KG, Kleinostheim, Germany]), contrast sensitivity assessment by FACT (Stereo Optical Co., Inc., Chicago, Ilinois, USA), and aberrometry (I Trace, Hoya,Tokyo, Japan).

A pre-operative consent for the ReLEx SMILE procedure was taken from all patients. The study was conducted in agreement with the Declaration of Helsinki and was approved by Nethradhama Superspeciality Eye Hospital Institutional Ethics Committee. The study was also registered with the Clinical Trials Registry of India (CTRI).

\section{Topographic examination}

Topographic examinations were performed pre-operatively and 3 months post-operatively with the SIRIUS, a threedimensional rotating Scheimpflug camera with a Placido disc topographer. Both, anterior and posterior surfaces of the cornea were examined for curvature changes in terms of mean keratometric power and asphericity ( $Q$-value) at 3, 5 , and $7 \mathrm{~mm}$ zones from the center.

The SIRIUS Scheimpflug Analyzer integrates a Placido disc and a mono rotating Scheimpflug system for corneal topography and three-dimensional analysis of the anterior eye segment. The aim of integration of Placido disc SIRIUS is to enhance the analysis of the anterior corneal surface.

Nasser et $\mathrm{a} \mathrm{l}^{17}$ and Hernández-Camarena et $\mathrm{al}{ }^{18}$ have found that the SIRIUS showed good to excellent repeatability for all measured parameters and that agreement analysis suggested that SIRIUS and Pentacam should not be used interchangeably.

\section{Surgical technique}

All surgeries were performed by a single experienced surgeon under topical anesthesia using the VisuMax femtosecond laser (Carl Zeiss Meditec AG, Jena, Germany).

The patient was positioned under the curved contact glass of the femtosecond laser and asked to fixate on a flashing target. When appropriate centration on the visual axis was observed, suction was applied.

Femtosecond laser pulses $(500 \mathrm{kHz})$ was used, first in a spiral-in pattern to achieve the cut at the deeper plane of intra-stromal lenticule, followed by spiral-out laser for superficial cut. The lenticule diameter (optical zone) was 6-7 mm and cap thickness of $100 \mu \mathrm{m}$. The laser cut energy index was 33 (corresponding to approximately $165 \mathrm{~mJ}$ ), and spot spacing of $4.5 \mu \mathrm{m}$. A $2 \mathrm{~mm}$ incision was created by the femto laser located at the 12 o'clock position. Following creation of lenticule, the incision was opened to identify 
Table I Number of patients, Intraocular pressure \& Residual bed thickness

\begin{tabular}{lllll}
\hline Group & Patients $(\mathbf{n})$ & $\begin{array}{l}\text { Pre-op IOP } \\
(\mathbf{m m H g})\end{array}$ & $\begin{array}{l}\text { Post-op IOP } \\
(\mathbf{m m H g})\end{array}$ & $\begin{array}{l}\text { Residual bed } \\
\text { thickness }(\mu \mathbf{m})\end{array}$ \\
\hline Low myopia & 3 & $13 \pm 1.73$ & $8.33 \pm 0.57$ & $368 \pm 32.51$ \\
Moderate myopia & 29 & $14.1 \pm 3.29$ & $12.65 \pm 2.91$ & $351.62 \pm 41.15$ \\
High myopia & 20 & $14.69 \pm 2.22$ & $11.85 \pm 2.75$ & $318 \pm 32.04$ \\
\hline
\end{tabular}

Note: Data are presented as Mean \pm SD.

Abbreviations: IOP, intraocular pressure; post-op, post-operative; pre-op, pre-operative.

the two planes of lenticule. A thin blunt spatula was used to dissect the superficial and deep planes of the lenticule and to break the remaining tissue bridges, thus separating the lenticule from the surrounding stroma. This lenticule was grasped with a pair of forceps and extracted through the superior incision. The corneal interface was then flushed with balanced salt solution.

\section{Statistical analysis}

Pre-operative and post-operative parameters as well as preoperative versus post-operative changes were analyzed using Statistical Package for the Social Sciences software (version 15, SPSS Inc, Chicago, IL, USA), analysis of variance, chisquare, and Fisher's exact test. A $P$-value $<0.05$ was considered to be statistically significant.

\section{Results}

The study included 52 eyes from 26 patients who satisfied the inclusion criteria.

Patients were divided into three groups on the basis of the degree of myopia as follows:

- Low myopia: myopia of -3 D or less SE (spherical equivalent)

- Moderate myopia: myopia between -3 and -6 D SE

- High myopia: myopia of -6 D or more SE

The mean age in the low, moderate, and high myopia group was $23.00 \pm 0.00,28.10 \pm 6.87$, and $29.50 \pm 5.50$ years, respectively.

The mean optical zone in the low, moderate, and high myopia group was $6.63 \pm 0.23,6.54 \pm 0.26$, and $6.20 \pm 0.21 \mathrm{~mm}$, respectively.
Tables 1 and 2 give data regarding number of patients in each group, the residual bed thickness, and the other preoperative and post-operative measured parameters.

\section{Changes in pachymetry}

Central corneal thickness showed a statistically significant decrease post-operatively in all the three groups. $P$-values $0.042,<0.001$, and $<0.001$ for low, moderate, and high myopia, respectively (Table 3 ).

\section{Anterior surface analysis}

Three months post-operatively, a statistically significant decrease in mean keratometric power at the anterior corneal surface was detected in moderate and high myopia group in 3,5 , and $7 \mathrm{~mm}$ zones $(P<0.001)$, and in low myopia group in 3 and $7 \mathrm{~mm}$ zone ( $P$-values 0.035 and 0.029$)$. The decrease in mean keratometric power at anterior corneal surface was not significant in low myopia group in the $5 \mathrm{~mm}$ zone $(P=0.114)$ (Table 4).

Asphericity ( $Q$-value) of the anterior surface changed significantly $(P<0.001)$ in moderate and high myopia group in 3,5 , and $7 \mathrm{~mm}$ zones, in which it changed from prolate to oblate, and in low myopia group in $5 \mathrm{~mm}$ zone, in which it changed to being less prolate; but there was no significant change in $Q$-value in low myopia group in 3 and $7 \mathrm{~mm}$ zones ( $P$-values 0.635 and 0.833 ) (Table 5).

\section{Posterior surface analysis}

A statistically significant increase in mean keratometric power in 3, 5 , and $7 \mathrm{~mm}$ zones of the posterior corneal surface compared with its pre-ReLEx SMILE value was detected after 3 months in the moderate and high myopia group $(P<0.001)$,

Table 2 Refractive error (Diopters) and Visual acuity (in LogMAR scale)

\begin{tabular}{|c|c|c|c|c|c|c|c|}
\hline & \multicolumn{3}{|l|}{ Pre-op } & \multicolumn{4}{|l|}{ Post-op } \\
\hline & DS (D) & DCYL (D) & BCVA & DS (D) & DCYL (D) & UCVA & BCVA \\
\hline Low myopia & $-2.17 \pm 0.14$ & $-0.67 \pm 0.38$ & $0.00 \pm 0.00$ & $-0.12 \pm 0.04$ & $-0.09 \pm 0.04$ & $0.00 \pm 0.00$ & $0.00 \pm 0.00$ \\
\hline Moderate myopia & $-3.68 \pm 0.75$ & $-0.81 \pm 0.48$ & $0.03 \pm 0.06$ & $-0.22 \pm 0.19$ & $-0.16 \pm 0.08$ & $-0.01 \pm 0.05$ & $-0.04 \pm 0.05$ \\
\hline High myopia & $-6.36 \pm 1.37$ & $-1.34 \pm 0.67$ & $0.006 \pm 0.02$ & $-0.35 \pm 0.28$ & $-0.24 \pm 0.17$ & $0.006 \pm 0.04$ & $-0.04 \pm 0.05$ \\
\hline
\end{tabular}

Note: Data are presented as Mean \pm SD.

Abbreviations: DCYL, diopter cylinder; DS, diopter sphere; D, diopters; post-op, post-operative; pre-op, pre-operative; UCVA, uncorrected distant visual acuity; $\mathrm{BCVA}$, best corrected distant visual acuity. 
Table 3 Pre-operative (pre-op) and post-operative (post-op) pachymetry

\begin{tabular}{llll}
\hline $\begin{array}{l}\text { Central corneal } \\
\text { thickness }\end{array}$ & $\begin{array}{l}\text { Low } \\
\text { myopia }\end{array}$ & $\begin{array}{l}\text { Moderate } \\
\text { myopia }\end{array}$ & $\begin{array}{l}\text { High } \\
\text { myopia }\end{array}$ \\
\hline Pre-op $(\mu \mathrm{m})$ & $547.67 \pm 24.01$ & $550.48 \pm 35.54$ & $532.15 \pm 33.81$ \\
Post-op $(\mu \mathrm{m})$ & $468.33 \pm 43.13$ & $454.10 \pm 43.70$ & $400.90 \pm 38.15$ \\
P-value & 0.042 & $<0.001$ & $<0.001$ \\
\hline
\end{tabular}

Note: Data are presented as Mean \pm SD.

but the change was not statistically significant in low myopia group ( $P$-values $0.143,0.347$, and 0.135 in 3,5 , and $7 \mathrm{~mm}$ zones, respectively) (Table 6).

Changes in asphericity ( $Q$-value) of the posterior surface suggested increased prolateness, and these findings were statistically significant $(P<0.001)$ in moderate myopia group in all three zones and in high myopia group in 3 and $7 \mathrm{~mm}$ zones. But there was no significant change in the $Q$-value in low myopia group in any of the three zones ( $P$-values 0.170 , 0.151 , and 0.145 in 3, 5 , and $7 \mathrm{~mm}$ zones, respectively) and in high myopia group in the $5 \mathrm{~mm}$ zone $(P=0.228)$ (Table 7).

\section{Changes in power and asphericity in relation to optical zone}

The change in mean keratometric power and asphericity of the posterior surface was more in the larger optical zone (6.51$7.00 \mathrm{~mm}$ ) compared to small optical zone $(6.00-6.50 \mathrm{~mm})$; however, the change was not statistically significant $(P>0.05)$ (Table 8).

\section{Discussion}

Refractive surgery is intended to change the shape of the anterior surface of the cornea, thus changing its refractive power. Since the surgery affects the anterior corneal surface

Table 4 Comparison of corneal keratometric power of anterior surface at 3, 5, and $7 \mathrm{~mm}$ zones before and 3 months after ReLEx SMILE

\begin{tabular}{|c|c|c|c|}
\hline $\begin{array}{l}\text { Corneal power: } \\
\text { anterior surface }\end{array}$ & $\begin{array}{l}\text { Low } \\
\text { myopia }\end{array}$ & $\begin{array}{l}\text { Moderate } \\
\text { myopia }\end{array}$ & $\begin{array}{l}\text { High } \\
\text { myopia }\end{array}$ \\
\hline \multicolumn{4}{|l|}{$3 \mathrm{~mm}$} \\
\hline Pre-op (D) & $42.49 \pm 1.98$ & $43.86 \pm 1.47$ & $43.64 \pm 0.43$ \\
\hline Post-op (D) & $39.33 \pm 1.58$ & $39.95 \pm 1.88$ & $38.99 \pm 1.26$ \\
\hline$P$-value & 0.035 & $<0.001$ & $<0.001$ \\
\hline \multicolumn{4}{|l|}{$5 \mathrm{~mm}$} \\
\hline Pre-op (D) & $42.34 \pm 1.96$ & $43.78 \pm 1.49$ & $43.57 \pm 0.44$ \\
\hline Post-op (D) & $39.20 \pm 1.58$ & $39.96 \pm 1.83$ & $39.07 \pm 1.14$ \\
\hline$P$-value & 0.114 & $<0.001$ & 0.047 \\
\hline \multicolumn{4}{|l|}{$7 \mathrm{~mm}$} \\
\hline Pre-op (D) & $42.10 \pm 1.88$ & $43.60 \pm 1.49$ & $43.42 \pm 0.44$ \\
\hline Post-op (D) & $39.07 \pm 1.47$ & $39.99 \pm 1.78$ & $39.27 \pm 0.95$ \\
\hline$P$-value & 0.029 & $<0.001$ & $<0.001$ \\
\hline
\end{tabular}

Note: Data are presented as Mean \pm SD.

Abbreviations: D, diopter; post-op, post-operative; pre-op, pre-operative; ReLEx SMILE, Refractive Small Incision Lenticule Extraction.
Table 5 Comparison of corneal asphericity of anterior surface at 3, 5, and $7 \mathrm{~mm}$ zones before and 3 months after ReLEx SMILE

\begin{tabular}{llll}
\hline $\begin{array}{l}\text { Corneal asphericity } \\
\text { (Q-value): anterior surface }\end{array}$ & $\begin{array}{l}\text { Low } \\
\text { myopia }\end{array}$ & $\begin{array}{l}\text { Moderate } \\
\text { myopia }\end{array}$ & $\begin{array}{l}\text { High } \\
\text { myopia }\end{array}$ \\
\hline 3 mmQ & & & \\
$\quad$ Pre-op & $-0.20 \pm 0.14$ & $-0.21 \pm 0.21$ & $-0.24 \pm 0.23$ \\
$\quad \begin{array}{l}\text { Post-op } \\
\text { P-value }\end{array}$ & $0.25 \pm 0.16$ & $0.45 \pm 0.68$ & $0.04 \pm 0.49$ \\
$5 \mathrm{mmQ}$ & 0.653 & 0.015 & $<0.001$ \\
$\quad \begin{array}{lll}\text { Pre-op } \\
\text { Post-op }\end{array}$ & $-0.37 \pm 0.13$ & $-0.27 \pm 0.15$ & $-0.28 \pm 0.18$ \\
P-value & $-0.47 \pm 0.22$ & $-0.03 \pm 0.43$ & $0.57 \pm 0.45$ \\
7 mmQ & 0.026 & $<0.001$ & $<0.001$ \\
$\quad$ Pre-op & & & \\
Post-op & $-0.35 \pm 0.07$ & $-0.30 \pm 0.13$ & $-0.32 \pm 0.14$ \\
$P$-value & $-0.33 \pm 0.16$ & $0.05 \pm 0.36$ & $0.63 \pm 0.44$ \\
\hline
\end{tabular}

Note: Data are presented as Mean \pm SD.

Abbreviations: post-op, post-operative; pre-op, pre-operative; ReLEx SMILE, Refractive Small Incision Lenticule Extraction.

and weakens the cornea, a modification in the posterior corneal surface may be expected. ${ }^{19}$

It has been shown that steepening of the posterior surface of cornea by a given amount has a smaller effect on the overall refraction of the eye than flattening of the anterior surface. This is due to small refractive index difference between the cornea and the aqueous. It has been found that a change of $0.2 \mathrm{D}$ at the back surface equals a change of around $2.0 \mathrm{D}$ at the front surface because of differences in the refractive indices. ${ }^{20}$

Our study demonstrated significant posterior corneal curvature changes after ReLEx SMILE in patients with moderate and high myopia; however, these changes were not significant for low myopia. There are many concerns about the correct alignment when comparing the changes of height against a best-fit sphere. Thus, similar to a study by Seitz et al, ${ }^{7}$ we measured parameters which are not as much

Table 6 Comparison of corneal keratometric power of posterior surface at 3, 5, and $7 \mathrm{~mm}$ zones before and 3 months after ReLEx SMILE

\begin{tabular}{llll}
\hline $\begin{array}{l}\text { Corneal power: } \\
\text { posterior surface }\end{array}$ & $\begin{array}{l}\text { Low } \\
\text { myopia }\end{array}$ & $\begin{array}{l}\text { Moderate } \\
\text { myopia }\end{array}$ & $\begin{array}{l}\text { High } \\
\text { myopia }\end{array}$ \\
\hline $3 \mathrm{~mm}$ & & & \\
$\quad \begin{array}{lll}\text { Pre-op (D) } \\
\text { Post-op (D) }\end{array}$ & $-5.87 \pm 0.17$ & $-6.14 \pm 0.23$ & $-6.19 \pm 0.16$ \\
$\quad-6.06 \pm 0.29$ & $-6.29 \pm 0.22$ & $-6.4 \pm 0.18$ \\
P-value & 0.143 & $<0.00 \mathrm{I}$ & $<0.00 \mathrm{I}$ \\
$5 \mathrm{~mm}$ & & & \\
$\quad$ Pre-op (D) & $-5.87 \pm 0.19$ & $-6.14 \pm 0.23$ & $-6.2 \mathrm{I} \pm 0.15$ \\
Post-op (D) & $-6.02 \pm 0.27$ & $-6.26 \pm 0.23$ & $-6.37 \pm 0.17$ \\
P-value & 0.347 & 0.014 & $<0.00 \mathrm{I}$ \\
7 mm & & & \\
$\quad \begin{array}{l}\text { Pre-op (D) } \\
\text { Post-op (D) }\end{array}$ & $-5.88 \pm 0.19$ & $-6.14 \pm 0.23$ & $-7.0 \mathrm{I} \pm 2.40$ \\
P-value & $-5.99 \pm 0.27$ & $-6.23 \pm 0.24$ & $-6.34 \pm 0.17$ \\
\hline
\end{tabular}

Note: Data are presented as Mean \pm SD.

Abbreviations: D, diopter; post-op, post-operative; pre-op, pre-operative; ReLEx SMILE, Refractive Small Incision Lenticule Extraction. 
Table 7 Comparison of corneal asphericity of posterior surface at 3, 5, and $7 \mathrm{~mm}$ zones before and 3 months after ReLEx SMILE

\begin{tabular}{llll}
\hline $\begin{array}{l}\text { Corneal asphericity } \\
\text { (Q-value): posterior surface }\end{array}$ & $\begin{array}{l}\text { Low } \\
\text { myopia }\end{array}$ & $\begin{array}{l}\text { Moderate } \\
\text { myopia }\end{array}$ & $\begin{array}{l}\text { High } \\
\text { myopia }\end{array}$ \\
\hline $3 \mathrm{~mm} Q$ & & & \\
Pre-op & $0.23 \pm 0.43$ & $0.00 \pm 0.28$ & $0.18 \pm 0.4 \mathrm{I}$ \\
Post-op & $-0.40 \pm 0.7 \mathrm{I}$ & $-0.28 \pm 0.56$ & $-0.34 \pm 0.39$ \\
$\quad P$-value & 0.170 & $<0.00 \mathrm{I}$ & $<0.00 \mathrm{I}$ \\
$5 \mathrm{~mm} Q$ & & & \\
$\quad$ Pre-op & $-0.10 \pm 0.16$ & $-0.10 \pm 0.17$ & $-0.04 \pm 0.20$ \\
Post-op & $-0.5 \mathrm{I} \pm 0.27$ & $-0.37 \pm 0.32$ & $-0.45 \pm 0.22$ \\
P-value & $0.15 \mathrm{I}$ & $<0.001$ & 0.228 \\
7 mmQ & & & \\
Pre-op & $-0.14 \pm 0.1 \mathrm{I}$ & $-0.15 \pm 0.13$ & $-0.08 \pm 0.16$ \\
Post-op & $-0.40 \pm 0.13$ & $-0.35 \pm 0.23$ & $-0.34 \pm 0.16$ \\
$P$-value & 0.145 & $<0.001$ & $<0.001$ \\
\hline
\end{tabular}

Abbreviations: post-op, post-operative; pre-op, pre-operative; ReLEx SMILE, Refractive Small Incision Lenticule Extraction.

subject to alignment accuracy and decided for the posterior power and asphericity ( $Q$-value).

Recent studies did not show significant posterior corneal curvature changes after laser refractive surgery. ${ }^{21-24}$ Ciolino and Belin ${ }^{21}$ did not observe significant posterior corneal surface displacement after LASIK and photorefractive keratectomy, using Pentacam Scheimpflug system. In addition, posterior corneal displacement was not significantly different between the LASIK and photorefractive keratectomy patients.

Studies by Seitz et $\mathrm{al}^{7}$ and Wang et $\mathrm{al}^{16}$ found a statistically significant increase of the negative central power and the oblate asphericity of the posterior curvature after LASIK. These changes, although small, correlated significantly with the amount of correction. In addition, the change of posterior power was significantly more pronounced with a presumed residual stromal bed thickness of $250 \mu \mathrm{m}$ and less.

Contrary to results in LASIK, we observed significant changes in posterior curvature and asphericity after ReLEx SMILE for moderate and high myopia, although results were not significant for low myopia. We found that a statistically significant increase of negative central power of the posterior curvature in the moderate and high myopia group was accompanied by an increase in the prolate asphericity of the posterior curvature in these groups.
We propose a theory for possible explanation of the conflicting results seen in our study. In LASIK, the Bowman's membrane $(8-14 \mu)$ is cut, thus reducing the biomechanical strength of the cornea. Because the flap does not contribute to the biomechanical stability of the cornea after its repositioning to the stromal bed, the residual corneal bed thickness is a crucial factor to prevent subsequent iatrogenic "keratectasias".

In ReLEx SMILE, the Bowman's membrane remains intact as the lenticule is removed from stroma through a small incision leaving behind a gap or space in the interface. The depth of this gap depends upon the amount of tissue removed, which in turn depends upon the degree of myopia. Hence, for higher powers, this gap is more. In due course of time, as the interface heals, this space collapses by posterior shift of the anterior surface and anterior shift of the posterior surface of the cornea. Due to preservation of strong Bowman's layer and compact anterior corneal lamellae, the movement of anterior surface is not significant compared to the posterior surface. This may be due to the fact that the Descemet's membrane $(5-10 \mu)$ is relatively more elastic and hence bulges forward under the effect of IOP.

This theory may explain the increase of negative keratometric power and prolate asphericity of the posterior curvature observed in this study, and also the under correction seen after ReLEx SMILE in higher powers, as seen in some studies. ${ }^{11,25-29}$

The change in keratometric power and asphericity of the posterior surface was found to be more in the larger optical zone $(6.51-7.00 \mathrm{~mm})$. However, when the large and small optical zones $(6.00-6.50 \mathrm{~mm})$ were compared, the difference in change of mean keratometric power and asphericity was not statistically significant. A larger sample size may be required to find any significant correlation between the optical zone and the change in mean keratometric power and asphericity.

To the best of our knowledge, this is the first report on posterior corneal curvature changes after ReLEx SMILE. As this study describes short-term results, it is not clear at this time whether our findings are due to an instantaneous biomechanical change caused by the surgery, or whether these

Table 8 Change in corneal keratometric power and asphericity in relation to optical zone

\begin{tabular}{|c|c|c|c|c|c|c|}
\hline & \multicolumn{3}{|c|}{ Change in keratometric power (D) } & \multicolumn{3}{|c|}{ Change in asphericity } \\
\hline & $\begin{array}{l}\text { Optical zone } \\
6.00-6.50 \mathrm{~mm}\end{array}$ & $\begin{array}{l}\text { Optical zone } \\
6.5 \mathrm{I}-7.00 \mathrm{~mm}\end{array}$ & $P$-value & $\begin{array}{l}\text { Optical zone } \\
6.00-6.50 \mathrm{~mm}\end{array}$ & $\begin{array}{l}\text { Optical zone } \\
6.5 \mathrm{I}-7.00 \mathrm{~mm}\end{array}$ & $P$-value \\
\hline Change in $3 \mathrm{~mm}$ zone & $0.17 \pm 0.12$ & $0.22 \pm 0.09$ & 0.328 & $0.36 \pm 0.53$ & $0.57 \pm 0.63$ & 0.325 \\
\hline Change in $5 \mathrm{~mm}$ zone & $0.13 \pm 0.10$ & $0.17 \pm 0.07$ & 0.306 & $0.31 \pm 0.32$ & $0.4 I \pm 0.27$ & 0.412 \\
\hline Change in $7 \mathrm{~mm}$ zone & $0.26 \pm 1.63$ & $0.13 \pm 0.05$ & 0.506 & $0.21 \pm 0.18$ & $0.32 \pm 0.20$ & 0.113 \\
\hline
\end{tabular}

Note: Data are presented as Mean \pm SD.

Abbreviation: $\mathrm{D}$, diopter. 
changes tend to progress over time. Nevertheless, results of the present study may have important practical implications for refining nomograms for correction of higher refractive errors with ReLEx SMILE. Further research with long-term follow-up is required to validate this theory and results of this study.

\section{Disclosure}

The authors report no conflicts of interest in this work.

\section{References}

1. Hersh PS, Scher KS, Irani R. Corneal topography of photorefractive keratectomy versus laser in situ keratomileusis. Summit PRK-LASIK Study Group. Ophthalmology. 1998;105:612-619.

2. Knorz MC, Wiesinger B, Liermann A, Seiberth V, Liesenhoff H. Laser in situ keratomileusis for moderate and high myopia and myopic astigmatism. Ophthalmology. 1998;105:932-940.

3. Hersh PS, Shah SI. Corneal topography of excimer laser photorefractive keratectomy using a 6-mm beam diameter. Summit PRK Topography Study Group. Ophthalmology. 1997;104:1333-1342.

4. Smolek MK, Oshika T, Klyce SD, Maeda N, Haight DH, McDonald MB. Topographic assessment of irregular astigmatism after photorefractive keratectomy. J Cataract Refract Surg. 1998;24:1079-1086.

5. Hernández-Quintela E, Samapunphong S, Khan BF, et al. Posterior corneal surface changes after refractive surgery. Ophthalmology. 2001; 108:1415-1422.

6. Baek T, Lee K, Kagaya F, Tomidokoro A, Amano S, Oshika T. Factors affecting the forward shift of posterior corneal surface after laser in situ keratomileusis. Ophthalmology. 2001;108(2):317-320.

7. Seitz B, Torres F, Langenbucher A, Behrens A, Suárez E. Posterior corneal curvature changes after myopic laser in situ keratomileusis. Ophthalmology. 2001;108:666-672; discussion 673.

8. Lee DH, Seo S, Won Jeong KW, Shin SC, Vukich JA. Early spatial changes in the posterior corneal surface after laser in situ keratomileusis. $J$ Cataract Refract Surg. 2003;29:778-784.

9. Twa MD, Roberts C, Mahmoud AM, Chang JS Jr. Response of the posterior corneal surface to laser in situ keratomileusis for myopia. J Cataract Refract Surg. 2005;31:61-71.

10. Cairns G, McGhee CN. Orbscan computerized topography: attributes, applications, and limitations. J Cataract Refract Surg. 2005;31: 205-220.

11. Shah R, Shah S, Sengupta S. Results of small incision lenticule extraction: all-in-one femtosecond laser refractive surgery. J Cataract Refract Surg. 2011;37:127-137.

12. Wang $\mathrm{Y}, \mathrm{Wu} Z$, Tang $\mathrm{X}$, et al. [Two millimeter micro incision lenticule extraction surgery with minimal invasion: a preliminary clinical report]. Zhonghua Yan Ke Za Zhi. 2014;50(9):671-680. Chinese.

13. Pedersen IB, Bak-Nielsen S, Vestergaard AH, Ivarsen A, Hjortdal J. Corneal biomechanical properties after LASIK, ReLEx flex, and ReLEx SMILE by Scheimpflug-based dynamic tonometry. Graefes Arch Clin Exp Ophthalmol. 2014;252(8):1329-1335.

Clinical Ophthalmology

\section{Publish your work in this journal}

Clinical Ophthalmology is an international, peer-reviewed journal covering all subspecialties within ophthalmology. Key topics include: Optometry; Visual science; Pharmacology and drug therapy in eye diseases; Basic Sciences; Primary and Secondary eye care; Patient Safety and Quality of Care Improvements. This journal is indexed on Submit your manuscript here: http://www.dovepress.com/clinical-ophthalmology-journal
14. Lin F, Xu Y, Yang Y. Comparison of the visual results after ReLEx SMILE and femtosecond laser-assisted LASIK for myopia. $J$ Refract Surg. 2014;30:248-254.

15. Xu Y, Yang Y. Dry eye after small incision lenticule extraction and LASIK for myopia. J Refract Surg. 2014;30:186-190.

16. Wang Z, Chen J, Yang B. Posterior corneal surface topographic changes after laser in situ keratomileusis are related to residual corneal bed thickness. Ophthalmology. 1999;106:406-409; discussion 409-410.

17. Nasser CK, Singer R, Barkana Y, Zadok D, Avni I, Goldich Y. Repeatability of the Sirius imaging system and agreement with the Pentacam HR. $J$ Refract Surg. 2012;28(7):493-497. doi: 10.3928/1081597X20120619-01.

18. Hernández-Camarena JC, Chirinos-Saldaña P, Navas A, et al. Repeatability, reproducibility, and agreement between three different Scheimpflug systems in measuring corneal and anterior segment biometry. J Refract Surg. 2014;30(9):616-621.

19. Dupps WJ Jr. Biomechanical modeling of corneal ectasia. J Refract Surg. 2005;21:186-190.

20. Seitz B, Langenbucher A. Intraocular lens power calculations in eyes after corneal refractive surgery. J Refract Surg. 2000;16:349-361.

21. Ciolino JB, Belin MW. Changes in the posterior cornea after laser in situ keratomileusis and photorefractive keratectomy. J Cataract Refract Surg. 2006;32:1426-1431.

22. Hashemi H, Mehravaran S. Corneal changes after laser refractive surgery for myopia: comparison of Orbscan II and Pentacam findings. $J$ Cataract Refract Surg. 2007;33:841-847.

23. Azar DT, Koch DD, editors. LASIK Fundamentals, Surgical Techniques and Complications. CRC Press: Boca Raton, chapter. 2002; 11:163-170.

24. Khairat YM, Mohamed YH, Moftah IA, Fouad NN. Evaluation of corneal changes after myopic LASIK using the Pentacam. Clin Ophthalmol. 2013;7:1771-1776.

25. Hjortdal JO, Vestergaard AH, Ivarsen A, Ragunathan S, Asp S. Predictors for the outcome of small-incision lenticule extraction for myopia. $J$ Refract Surg. 2012;28:865-871.

26. Vestergaard A, Ivarsen AR, Asp S, Hjortdal JO. Small-incision lenticule extraction for moderate to high myopia: predictability, safety, and patient satisfaction. J Cataract Refract Surg. 2012;38:2003-2010.

27. Wang Y, Bao XL, Tang X, Zuo T, Geng WL, Jin Y. [Clinical study of femtosecond laser corneal small incision lenticule extraction for correction of myopia and myopic astigmatism]. Zhonghua Yan Ke Za Zhi. 2013;49:292-298. Chinese.

28. Sekundo W, Gertnere J, Bertelmann T, Solomatin I. One-year refractive results, contrast sensitivity, high-order aberrations and complications after myopic small-incision lenticule extraction (ReLEx SMILE). Graefes Arch Clin Exp Ophthalmol. 2014;252(5):837-843.

29. Agca A, Demirok A, Cankaya KI, et al. Comparison of visual acuity and higher-order aberrations after femtosecond lenticule extraction and small-incision lenticule extraction. Cont Lens Anterior Eye. 2014;37(4): 292-296.

PubMed Central and CAS, and is the official journal of The Society of Clinical Ophthalmology (SCO). The manuscript management system is completely online and includes a very quick and fair peer-review system, which is all easy to use. Visit http://www.dovepress.com/ testimonials.php to read real quotes from published authors. 